\title{
Radiation Treatment in Women with Ovarian Cancer: Past, Present, and Future
}

\author{
Emma C. Fields ${ }^{1}$, William P. McGuire ${ }^{2}$, Lilie Lin ${ }^{3}$ and Sarah M. Temkin ${ }^{4 *}$ \\ ${ }^{1}$ Division of Radiation Oncology, Virginia Commonwealth University, Richmond, VA, United States, ${ }^{2}$ Internal Medicine, Virginia \\ Commonwealth University, Richmond VA, United States, ${ }^{3}$ Division of Radiation Oncology, University of Texas, MD Anderson \\ Cancer Center, Houston, TX, United States, ${ }^{4}$ Division of Gynecologic Oncology, Virginia Commonwealth University, \\ Main Hospital, Richmond, VA, United States
}

OPEN ACCESS

Edited by:

Charles A. Kunos, National Institutes of Health,

United States

Reviewed by: Ivy A. Petersen,

Mayo Clinic, United States

Shiv K. Gupta,

Mayo Clinic, United States Timothy James Kinsella,

Alpert Medical School, Brown University, United States

*Correspondence: Sarah M. Temkin sarah.temkin@vcuhealth.org

Specialty section:

This article was submitted to Radiation Oncology,

a section of the journal

Frontiers in Oncology

Received: 10 April 2017 Accepted: 02 August 2017 Published: 21 August 2017

Citation:

Fields EC, McGuire WP, Lin L and

Temkin SM (2017) Radiation Treatment in Women with Ovarian Cancer: Past, Present, and Future.

Front. Oncol. 7:177.

doi: 10.3389/fonc.2017.00177
Ovarian cancer is the most lethal of the gynecologic cancers, with 5-year survival rates less than $50 \%$. Most women present with advanced stage disease as the pattern of spread is typically with dissemination of malignancy throughout the peritoneal cavity prior to development of any symptoms. Prior to the advent of platinum-based chemotherapy, radiotherapy was used as adjuvant therapy to sterilize micrometastatic disease. The evolution of radiotherapy is detailed in this review, which establishes radiotherapy as an effective therapy for women with micrometastatic disease in the peritoneal cavity after surgery, ovarian clear cell carcinoma, focal metastatic disease, and for palliation of advanced disease. However, with older techniques, the toxicity of whole abdominal radiotherapy and the advancement of systemic therapies have limited the use of radiotherapy in this disease. With newer radiotherapy techniques, including intensity-modulated radiotherapy (IMRT), stereotactic body radiotherapy (SBRT), and low-dose hyperfractionation in combination with targeted agents, radiotherapy could be reconsidered as part of the standard management for this deadly disease.

Keywords: ovarian cancer, radiation, novel therapeutics, poly(ADP-ribose) polymerase inhibitors, abscopal effect

\section{INTRODUCTION}

Epithelial ovarian cancer is the most lethal of the gynecologic cancers, with a 5-year survival rate less than $50 \%$. Each year, an estimated 22,000 women will be diagnosed with and 14,000 women will die from the disease (1). The emergence of molecular and genetic data over the past decade has improved the understanding of the heterogeneity of ovarian cancer. Type I tumors consist of low-grade serous, low-grade endometrioid, clear cell carcinomas, and mucinous carcinomas and are characterized by mutations in KRAS, BRAF, PTEN, PIK3CA, CTNNB1, ARID1A, and PPP2R1A. These cancers tend to be diagnosed while confined to the ovary and are relatively chemotherapy resistant. Type II ovarian cancers are the more common of the ovarian cancer histotypes, consisting of high-grade serous (70\%), high-grade endometrioid, carcinosarcoma, and undifferentiated carcinomas. Type II tumors are defined by TP53 mutations, which are rare in Type I cancers (2-5). Women diagnosed with Type II cancers typically present with few or vague symptoms. As a result, the majority of women present with Stage III or IV disease where disease is present in the upper abdomen or outside of the peritoneal cavity or within hepatic parenchyma.

With aggressive therapy at diagnosis, including surgery and platinum-based chemotherapy, more than $80 \%$ of women diagnosed with advanced disease will have an initial complete response. 
Unfortunately, these responses are infrequently durable and the majority of women with ovarian cancer develop recurrent, disease, which is typically incurable although subsequent response and months of survival may still be possible. Unfortunately, responses to subsequent chemotherapeutic regimens shorten in duration over time due to progressive development of resistance to platinum-based chemotherapy. Novel treatment strategies are urgently needed in order to improve survival.

Despite evidence that ovarian cancer is a radiosensitive malignancy, the use of radiation as a therapeutic modality in the modern era is limited (6-10). Ovarian cancer has a unique pattern of dissemination as transperitoneal spread is the most common route such that, diagnosis, the tumor is confined to the abdominal and pelvic cavity in approximately $85 \%$ of patients. Adjuvant radiation therapy was historically used in the adjuvant setting for the management of ovarian carcinoma of all tumor subtypes with reasonable results $(6,10)$. Because ovarian cancer is rarely confined to the pelvis, whole pelvic radiation is a largely ineffective method of disease control since it does not treat the entire volume at risk of recurrence. Whole abdominal radiotherapy (WAR) was used in the pre-chemotherapy era to sterilize large volumes of micrometastatic intraperitoneal disease. However, the low doses required to meet tolerance of the bowel, kidneys, and liver using two dimensional fields were ineffective in eradicating gross residual disease in the peritoneal cavity resulting in poor therapeutic efficacy. Additionally, the toxicity of radiation therapy was high particularly when using wide-field irradiation. High rates of both acute and late toxicity, particularly gastrointestinal, resulted in the abandonment of radiation in this disease particularly when cisplatin was confirmed to be a highly active systemic agent. Improved radiation techniques with lower toxicity have led to a renewed interest in the use of radiation therapy for metastatic cancers for many disease sites including ovarian cancer. In this article, we summarize the historical use of radiotherapy for ovarian cancer and discuss its potential role in the era of intensitymodulated radiotherapy (IMRT) and image guided radiotherapy as well as its integration with novel therapies.

\section{INTRAPERITONEAL P32}

In a colloidal suspension form, phosphorus-32 $\left({ }^{32} \mathrm{P}\right)$ forms a complex, insoluble particle, which can be injected directly into the peritoneal cavity. The colloidal suspension then prevents radioisotope from leaving the intended target and disseminating throughout the body $(11,12)$. The first reported clinical application of ${ }^{32} \mathrm{P}$ was in the 1930 s and other intraperitoneal radioactive isotypes were investigated in the 1950s and 1960s most notably ${ }^{198} \mathrm{Au}$, but for reasons of safety and toxicity, ${ }^{32} \mathrm{P}$ became the agent of choice for the treatment of ovarian cancer and the palliation of malignant ascites in the 1960s $(12,13)$. Many reports of therapeutic ${ }^{32} \mathrm{P}$ were encouraging (13-16).

\section{Advanced Disease}

For patients with advanced disease, ${ }^{32} \mathrm{P}$ combined with WAR was investigated but found to be overly toxic. In a review of 95 patients using ${ }^{32} \mathrm{P}$ for ovarian cancer, Tharp and Hornback demonstrated that the 5-year chronic complication rates (predominately gastrointestinal) were $44 \%$ when adjunctive pelvic or whole abdominal radiation was added compared with $17 \%$ (5\% if minor complaints excluded) if used alone $(p=0.04)(17)$. Klaassen and colleagues from the National Cancer Institute of Canada (NCIC), similarly abandoned further development of ${ }^{32} \mathrm{P}$ combined with pelvic radiotherapy in the treatment of high-risk early stage ovarian cancer due to excessive toxicity (18). Nevertheless, ${ }^{32} \mathrm{P}$ continued to be investigated as consolidation therapy for patients with advanced disease after pathologically documented (by second look laparotomy) complete remission following primary surgery and platinum-based surgery. A Gynecologic Oncology Group (GOG) study enrolled 202 patients who were randomized to ${ }^{32} \mathrm{P}$ vs. no further treatment following a negative second look surgery. No difference in relapse rates or survival was observed and toxicity was higher in the treatment arm (19).

\section{Early Stage Disease}

A large prospective clinical trial to assess the utility of ${ }^{32} \mathrm{P}$ in early stage ovarian cancer was opened in 1976 by the Ovarian Cancer Study Group and joined in 1978 by the GOG. Patients with Stage I, Grade 3 or Stage II disease were randomly assigned to receive either melphalan or intraperitoneal ${ }^{32} \mathrm{P}[15 \mathrm{mCi}$ of chromic phosphate (before 1979 the dose was $7.5 \mathrm{mCi}$ )] as primary postoperative adjuvant therapy. One hundred forty-five patients were randomly assigned, 71 to receive melphalan and 74 to receive ${ }^{32} \mathrm{P}$. The study was closed to new patients in November 1986 and no survival differences were seen in either arm (20). Criticisms of this trial include the inclusion of suboptimally staged patients (nodal sampling was not required) and patients with tumors of low malignant potential (22\%). Toxicity differences between the arms included increased late gastrointestianl toxicity in the ${ }^{32} \mathrm{P}$ arm and secondary hematologic malignancies in the melphalan arm. Despite these limitations, three subsequent prospective trials compared intraperitoneal ${ }^{32} \mathrm{P}$ to adjuvant chemotherapy in patients with early stage disease (20-23). Although survival was similar between arms, ${ }^{32} \mathrm{P}$ for early stage disease was abandoned due to the easier administration and lower toxicity of newer, improved systemic agents (platinum). An improved emphasis on surgical staging and a better understanding of the histologic subtypes of ovarian cancer led to better definitions of early stage patients in whom adjuvant therapy could be omitted in favor of close observation (24).

\section{WHOLE-ABDOMEN RADIATION THERAPY}

In the 1960s, a "moving strip" technique for the delivery of WAR was developed. Because available technology could not adequately deliver radiation to the entire abdomen, the patient's abdomen was marked with 12-14 "strips," each $2.5 \mathrm{~cm}$ in height, and treated for approximately 10 weeks. With daily fractions of 225-300 cGy, a cumulative dose of 2,250-3,000 cGy was able to be delivered (Figure 1A) $(25,26)$.

The development of open-field techniques as an alternative to the moving strip technique allowed daily treatment with shorter duration courses of radiation delivery. Both techniques have been compared prospectively for efficacy and toxicity and found to be similar $(27,28)$. Because the open field technique was 


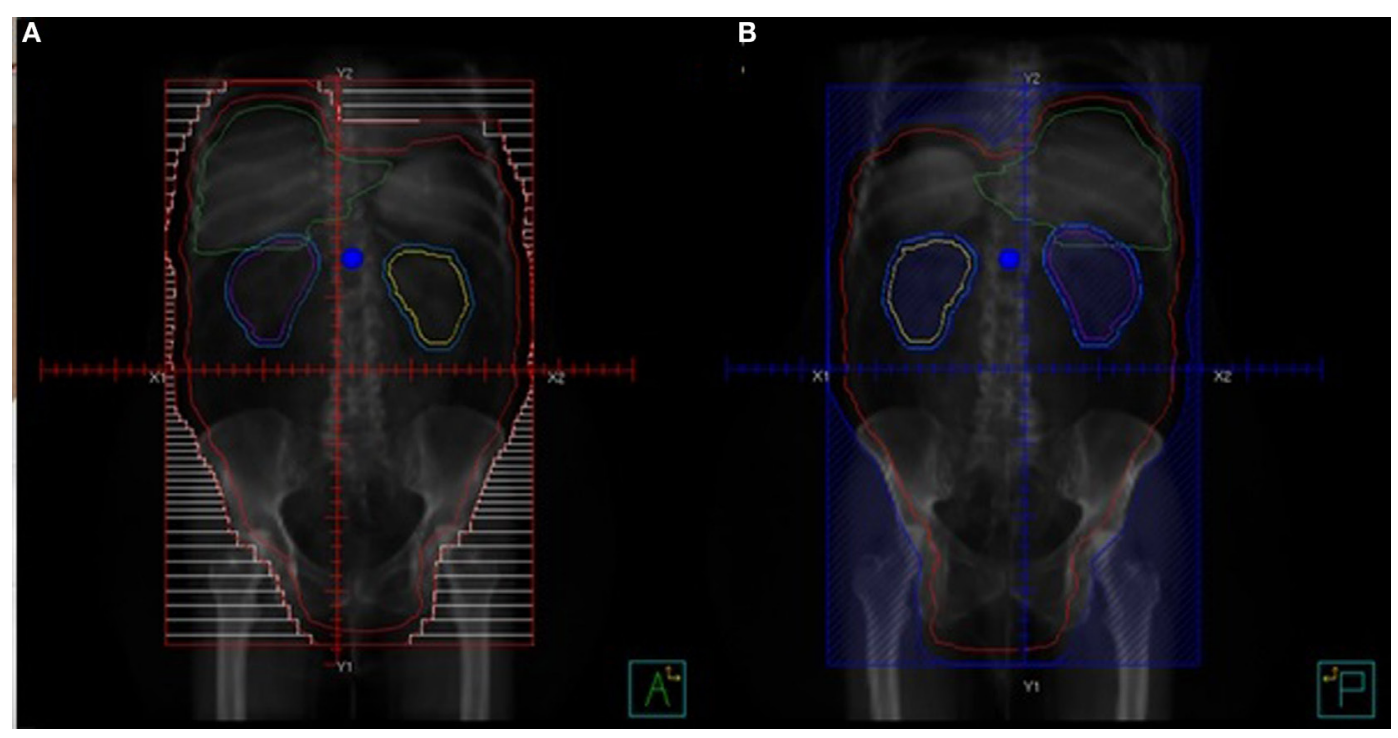

FIGURE 1 | Techniques for treating whole abdominal radiation. (A) Open field technique AP beam. (B) Open field technique PA beam with kidney blocks.

associated with fewer serious late toxicities, is simpler to plan, and takes less time to administer, it became the favorable technique (Figures 1A,B) $(26,28)$.

\section{Adjuvant WAR following Surgery}

Several prospective trials conducted in the 1970s showed promising results of postoperative radiation following surgery (Table 1) $(25,29-35)$. Although patients with bulky disease following surgery were rarely cured, those patients with microscopic residual disease after initial cytoreductive surgery experienced disease-free survivals of $42-62 \%$ at 10 years in two randomized trials (29, 30). The first of these trials randomized 149 patients with early ovarian cancer comparing WAR with additional irradiation to the pelvis and melphalan. Although improved survival was not demonstrated in the study population, a benefit for Stage I patients who received WAR was seen (29). A second study of pelvic radiation plus WAR compared to pelvic radiation plus chlorambucil did demonstrate an overall survival benefit ( 78 vs. $51 \%$; $p=0.006$ ) (30). The combined results of these two studies were used to justify the development of a risk model on the basis of stage, grade, and amount of residual disease to define categories of patients most likely to benefit from WAR $(10,26)$. Ideal patients for WAR were thought to be Stage I, Grade 2 or 3; Stage 2 disease except Grade 3 patients with residual disease; and Stage III, Grade 1 patients with $<2 \mathrm{~cm}$ residual disease (26).

Enthusiasm for this risk model was tempered by the results of a multicenter trial of 257 patients with Stage I, II, or IIIA disease who were randomized to WAR or melphalan or ${ }^{32} \mathrm{P}$ following whole pelvic radiation. The combination of pelvic radiation therapy plus ${ }^{32} \mathrm{P}$ was exceedingly toxic, and this arm was dropped after 44 patients were enrolled. Patients who received melphalan had improved disease-free survival but overall survival was similar between all three arms (31). Criticisms of this study included the number of inadequately surgically staged patients, a large number of protocol violations and the excessive radiation related toxicity.

Additional prospective trials of WAR vs. chemotherapy are included in Table 1. Radiation began to fall out of favor at this time as an adjuvant treatment modality due to the additional toxicity of WAR compared to chemotherapy, the complexities of radiation delivery compared to chemotherapy, and the advent of more effective cytotoxic agents for the treatment of ovarian cancer.

\section{Consolidation Therapy (following Surgery and Chemotherapy)}

During this era of ovarian cancer treatment, when the benefits of radiation were being evaluated, second look laparotomy was routinely performed after completion of primary therapy in ovarian cancer when imaging and markers suggested a complete clinical response. Patients with minimal residual disease at the time of second look surgery seemed most likely to have improved survival from WAR, and there were reports of long-term survivors in this subset of patients. Despite concerns about toxicity, the use of radiation as consolidation following surgery and chemotherapy continued to be explored $(38,42-46)$. Retrospective investigations demonstrated 3-year progression-free survival rates of $50-67 \%$ $(43,44)$ and 5-year overall survival rates of $40-66 \%(45,46)$.

The largest of the prospective trials examining consolidation WAR are presented in Table 1. The West Midlands Ovarian Cancer Group Trial II reported a prospective randomized comparison of WAR vs. 1 year of chlorambucil treatment. The randomization was done after primary surgery, chemotherapy, and second look surgery. Fifty-six patients were randomly assigned to receive WAR and 53 patients received chlorambucil after second look surgery. Methodologic problems as well as slow accrual make the results difficult to interpret, but survival was not statistically different between treatments (32). A subsequent Canadian trial compared chemotherapy alone to 3 cycles of cyclophosphamide 
TABLE 1 | Studies comparing whole abdominal radiotherapy (WAR) vs. chemotherapy.

\begin{tabular}{|c|c|c|c|c|c|}
\hline \multirow[t]{2}{*}{ Study } & \multirow[t]{2}{*}{$N$} & \multirow[t]{2}{*}{ Inclusion criteria } & \multirow[t]{2}{*}{ Treatment arms } & \multicolumn{2}{|c|}{ 5-year survival rates } \\
\hline & & & & WAR & $\begin{array}{l}\text { CHEMO } \\
(\%)\end{array}$ \\
\hline \multicolumn{6}{|l|}{ Adjuvant radiotherapy } \\
\hline $\begin{array}{l}\text { MDACC } \\
\text { Smith et al. (29) }\end{array}$ & 149 & Stage I-III & WAR vs. melphalan & $71 \%$ & 72 \\
\hline $\begin{array}{l}\text { Gynecologic Oncology Group } \\
\text { Hreshchyshyn et al. (36) }\end{array}$ & 86 & Stage I & No further therapy vs. WAR vs. melphalan & $\begin{array}{c}70 \%^{\mathrm{a}} \\
(p<0.05)\end{array}$ & 94 \\
\hline $\begin{array}{l}\text { Princess Margaret } \\
\text { Dembo et al. (30) }\end{array}$ & 147 & Stage I-III & PR + WAR vs. PR + cholorambucil & $\begin{array}{c}58 \%^{a} \\
(p<0.05)\end{array}$ & 41 \\
\hline $\begin{array}{l}\text { National Cancer Institute of Canada } \\
\text { Klaassen et al. (31) }\end{array}$ & 257 & Stage I-IIIA & $\begin{array}{l}\text { Arm A: WAR } \\
\text { Arm B: Melphalan + pelvic RT } \\
\text { Arm C: }{ }^{32} \mathrm{P}+\text { pelvic RT (dropped due to toxicity) }\end{array}$ & $61 \%$ & 62 \\
\hline $\begin{array}{l}\text { Denmark } \\
\text { Sell et al. (33) }\end{array}$ & 118 & Stage IB-II & WAR vs. cyclophosphamide + pelvic RT & $55 \%$ & 63 \\
\hline $\begin{array}{l}\text { West Midlands I } \\
\text { Redman et al. (32) }\end{array}$ & 40 & Stage IC-III, no residuum & WAR vs. 5 cycles cisplatin & $58 \%$ & 62 \\
\hline $\begin{array}{l}\text { National Cancer Institute (NCl) Italy } \\
\text { Chiara et al. (34) }\end{array}$ & 70 & Stage I-III & WAR vs. 6 cycles cisplatin + cyclophosphamide & $53 \%$ & 71 \\
\hline $\begin{array}{l}\text { French } \\
\text { Kojs et al. (35) }\end{array}$ & 150 & $\begin{array}{l}\text { Stage } I A, I B(G 2-3), I C, \| A \\
\text { no residuum }\end{array}$ & WAR vs. cisplatin, adriamycin, cyclophosphamide & $81 \%$ & 81 \\
\hline \multicolumn{6}{|l|}{ Consolidation radiotherapy } \\
\hline $\begin{array}{l}\text { West Midlands II } \\
\text { Lawton et al. (37) }\end{array}$ & 109 & $\begin{array}{l}\text { Surgery } \rightarrow \text { cisplatin } \times 5 \rightarrow \\
\text { second look surgery }\end{array}$ & $\begin{array}{l}\text { Arm A: WAR } \\
\text { Arm B: chlorambucil } \times 1 \text { year }\end{array}$ & $35 \%{ }^{\mathrm{b}}$ & $35^{b}$ \\
\hline $\begin{array}{l}\text { British Columbia } \\
\text { Hoskins et al. (38) }\end{array}$ & 131 & Stage IG3, IIG3, III no residuum & $\begin{array}{l}\text { Arm A (1983-1989): cisplatin }+ \text { cyclophosphamide } \times 6 \\
\text { cycles with WART between cycles } 3 \text { and } 4 \\
\text { Arm B (1989-1991): cisplatin } \times 6 \text { cycles }\end{array}$ & $78 \%$ & 78 \\
\hline $\begin{array}{l}\text { North Thames Ovary Study Group } \\
\text { Lambert et al. (39) }\end{array}$ & 117 & Stage IIB-IV $\leq 2 \mathrm{~cm}$ residuum & $\begin{array}{l}\text { Arm A: WAR } \\
\text { Arm B: carboplatin }\end{array}$ & $32 \%$ & 32 \\
\hline $\begin{array}{l}\text { Austrian } \\
\text { Pickel et al. (40) }\end{array}$ & 32 & $\begin{array}{l}\text { Stage IC-IV } \rightarrow \text { carboplatin, } \\
\text { epirubicin, prednimustine } \times 6\end{array}$ & $\begin{array}{l}\text { Arm: A: WAR } \\
\text { Arm B: observation }\end{array}$ & $\begin{array}{c}59 \%^{\mathrm{a}} \\
(p<0.05)\end{array}$ & 33 \\
\hline \multirow[t]{2}{*}{$\begin{array}{l}\text { Swedish } \\
\text { Sorbe and Swedish-Norgewian } \\
\text { Ovarian Cancer Study Group (41) }\end{array}$} & 172 & $\begin{array}{l}\text { III no or microscopic } \\
\text { residuum }(n=98)\end{array}$ & $\begin{array}{l}\text { Arm A: WAR } \\
\text { Arm B: chemotherapy } \\
\text { Arm C: no further therapy }\end{array}$ & $69 \%$ & 57 \\
\hline & & Macroscopic disease & $\begin{array}{l}\text { Arm A: WAR } \\
\text { Arm B: chemotherapy }\end{array}$ & $32 \%$ & 41 \\
\hline
\end{tabular}

10 year survival.

b2 year survival rates.

and cisplatin followed by WAR followed by three additional cycles of chemotherapy. Survival was improved for the subset of patients with Stage I disease although overall 5-year survival was equivalent in both arms (38). A prospective trial from the North Thames Ovary Study Group, randomized 117 patients with residual disease of $2 \mathrm{~cm}$ or less at second-look laparotomy or laparoscopy to receive consolidation therapy, with either additional carboplatin or WAR (24 Gy) with no difference in survival seen between arms but toxicity favored the chemotherapy arm (39). Additionally, a Swedish prospective study randomized 172 patients with stage III ovarian cancer to receive consolidative whole abdominal radiotherapy, further chemotherapy, or no additional therapy following second look laparotomy. For patients with pathologic CR $(n=98)$, there was significantly improved progression-free survival (56 vs. $36 \%$ ) and improved overall survival (69 vs. 57\%) favoring WAR $(p=0.032)$. In patient with microscopic residual disease $(n=74)$, there was no difference in progression free or overall survival between the two arms. No survival difference was seen in those patients with macroscopic disease. Late, grade 3 bowel toxicity was reported in $10 \%$ of patients (41). The only truly positive study examining WAR consolidation was an Austrian study with longterm follow-up which showed a relapse-free survival and overall survival benefit for WAR compared to observation after a clinical complete response to six cycles of triplet chemotherapy. This benefit was most pronounced in women with stage III disease with a relapse-free survival at 5 years of 45 vs. $19 \%(p=0.0061)$ and overall survival at 5 years of 59 vs. $26 \%(p=0.012)(40)$.

A recent Surveillance, Epidemiology, and End Results Program analysis demonstrated an overall worse survival for patients who received RT for ovarian cancer. Yet, interestingly, the subset of patients with Stage III disease who received RT had a better OS at 5 years ( 54 vs. $44 \%$ ) and 10 years (36 vs. $30 \%$, 
$p=0.037$ ) (47) compared to those who did not receive radiation. These results should be interpreted with caution due to the limitations of this database but provide continued support for some therapeutic role of radiation in a subset of ovarian cancer patients.

\section{Clear Cell Histology}

Ovarian clear cell carcinoma has discrete clinical and molecular characteristics compared with the most common serous histologic type (48). Part of the interest in using radiation in clear cell carcinoma of the ovary is the relative chemotherapeutic resistance of this histogenetic type of ovarian cancer compared to the more common serous histopathology (48). A population-based study from British Columbia, Canada suggested that WAR provides a survival benefit when added to chemotherapy particularly in lowstage disease. In this report, using retrospective data, patients with Stage IC ovarian clear cell carcinoma treated with carboplatin and paclitaxel followed by abdominopelvic radiation had statistically superior disease-free survival compared to patients who had no radiation after initial chemotherapy. The absolute increase in disease-free survival following radiation was $20 \%$ at 5 years (49). Nagai demonstrated a survival advantage for adjuvant radiation in 16 ovarian clear cell carcinoma patients, stage IC-III treated with WAR in comparison to 12 patients from a historical cohort that received postsurgical platinum-based chemotherapy (50). The improved progression-free survival correlated to a significantly improved 5-year overall survival in the RT group of 81.8 vs. $33.3 \%$. The methodological problems with this study include the small sample size, the comparator group of historic controls, as well as the potential selection bias in the prospective cohort. However, a very large retrospective Canadian study of 700 ovarian cancer patients treated with platinum-based chemotherapy alone or combination platinum-based chemotherapy combined with WAR, demonstrated a benefit from radiation for women with low-stage, microscopic residual disease, and non-serous histology - a $40 \%$ reduction in disease specific mortality at 10 years was observed (51). Conversely, a more recent Canadian retrospective review of 163 patients with early stage ovarian clear cell carcinoma treated at two institutions over a 20-year time period with or without adjuvant pelvic and/or WAR was not able to demonstrate a progression free or overall survival benefit (52). Furthermore, the most common patterns of failure were multifocal and distant, limiting the value of either pelvic radiation or WAR (53). These results in composite suggest a potential role for radiation therapy in ovarian cancer patients with low-stage clear cell histology; however, further research is needed to determine the most appropriate therapy for this group of patients.

\section{Toxicity of WAR-Why WAR Fell Out of Favor}

Despite the perceived benefits of radiotherapy in intermediate and high-risk epithelial ovarian cancer as well as clear cell ovarian cancer, WAR has largely fallen out of the standard treatment paradigm for ovarian cancer. Indeed, the toxicity of WAR was significant-few patients made it through a treatment course without side effects, some significant enough to halt completion of therapy. During treatment, acute toxicity included diarrhea, fatigue, nausea, and hematologic effects. More concerning, however, were the long-term toxicities, which included basal pneumonitis in up to $20 \%$ of patients, liver damage, and bowel toxicity (10-15\% of patients). Among 1,098 patients studied prospectively with WAR as ovarian cancer treatment, $5.6 \%$ underwent surgery for bowel obstruction, and there were four deaths related to bowel toxicity from radiation treatment (26). In addition to toxicity, the era of aggressive cytoreduction and effective chemotherapy (platinum agents) called into question the therapeutic index of radiation in the treatment of ovarian cancer.

\section{SALVAGE RT AND STEREOTACTIC BODY RADIOTHERAPY (SBRT)}

Radiation therapy for ovarian cancer has, therefore, been predominantly confined to the palliative setting, used for symptom control, or to treat localized metastatic disease. Several retrospective studies have demonstrated the utility of targeted involvedfield radiotherapy to doses of 45-60 Gy given in 1.8-2 Gy fractions (54-57). For patients with solitary recurrences, excellent local control (89-100\%) has been shown $(55,57)$. Despite being heavily pretreated with chemotherapy, similar rates of progression-free survival and statistically longer rates of median overall survival compared to a similar group of women who received salvage chemotherapy at the time of recurrence have been described (55, 56). Although thought provoking, these studies deserve caution as the sample sizes are small, a selection bias exists for patients treated with this modality and the patients in comparison arms may not have received contemporary chemotherapy regimens. With minimal long-term toxicities, involved-field radiotherapy allows for longer chemotherapy-free intervals and should be considered as part of the treatment paradigm for salvage therapy of isolated recurrences (54).

Stereotactic body radiotherapy (SBRT) is one of the newer options for palliative or salvage radiotherapy that allows for focused high-dose radiotherapy to the tumor with minimal dose to organs in close proximity and is ideal for residual or limited metastatic disease. SBRT is linear accelerator-based focal radiotherapy delivered with rigid patient and tumor immobilization, elegant dosimetry, and daily image guidance for verification of set up. SBRT implies a high-dose per fraction and is delivered in 2-5 fractions. SBRT serves to decrease tumor burden, destroy chemoresistant tumor clones, and help stimulate innate immune response or expose tumor neoantigens, providing excellent rates of local control, minimal acute and late toxicities, and can be used in women who have had prior radiotherapy (58-60). Figure 2 shows an SBRT plan treating a metastatic para-aortic lymph node in women with serous ovarian carcinoma who had previously received multiple lines of systemic therapy.

Multiple studies of SBRT in the management of metastatic gynecologic malignancies have been published (Table 2) (61-64). In a Phase II study, 50 women (50\% with primary ovarian cancer) with $\leq 4$ sites of metastatic disease were treated with SBRT to a dose 8 Gy $\times 3$ fractions using Cyberknife. Common treatment sites included para-aortic nodes (38\%), pelvic nodes (28\%), and the liver $(16 \%)$. The clinical target volumes were delineated based on co-registration to $\mathrm{PET} / \mathrm{CT}$ imaging and $3 \mathrm{~mm}$ were added to 


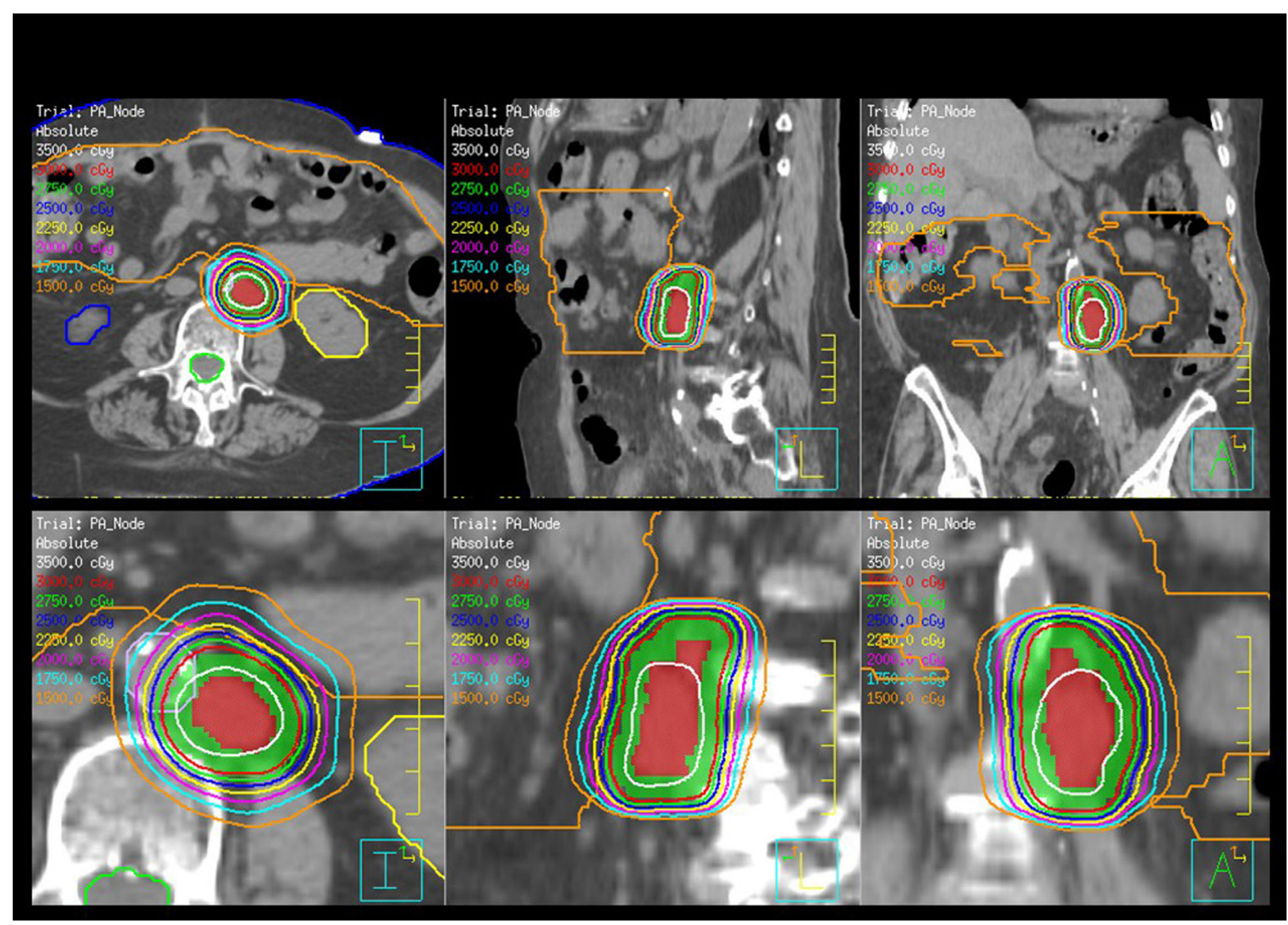

FIGURE 2 | Stereotactic body radiotherapy (SBRT) plan for the treatment of a para-aortic lymph node for a woman with recurrent serous ovarian cancer. The plan is shown in axial, sagittal, and coronal orientations. The planning target volume is color washed in green, the kidneys are yellow, and blue and the bowel is orange. The dose is 30 Gy and prescribed in five fractions.

TABLE 2 | Stereotactic body radiotherapy for recurrent/metastatic ovarian cancer.

\begin{tabular}{|c|c|c|c|c|c|}
\hline Study & $N$ & Inclusion criteria & SBRT dose & Local control & $\begin{array}{l}\text { Distant } \\
\text { progression }\end{array}$ \\
\hline $\begin{array}{l}\text { Phase II Cleveland SBRT } \\
\text { trial } \\
\text { Kunos et al. (61) }\end{array}$ & $\begin{array}{l}50 \mathrm{pts} \\
\text { (103 lesions) }\end{array}$ & $\begin{array}{l}\leq 4 \text { metastatic sites, ovarian, } \\
\text { cervical, endometrial cancers }\end{array}$ & 8 Gy $\times 3$ fractions daily & $96 \%$ at 6 months & $62 \%$ at 6 months \\
\hline $\begin{array}{l}\text { Italy } \\
\text { Deodato et al. (65) }\end{array}$ & $\begin{array}{l}11 \text { pts } \\
\text { (12 lesions) }\end{array}$ & $\begin{array}{l}\text { Confirmed recurrent/metastatic ovarian, } \\
\text { cervical, endometrial cancers }\end{array}$ & 6 Gy $\times 5$ fractions daily & $66.6 \%$ at 2 years & $46 \%$ at 2 years \\
\hline $\begin{array}{l}\text { University of California } \\
\text { Mesko et al. (67) }\end{array}$ & $\begin{array}{l}28 \text { patients } \\
\text { (47 lesions) }\end{array}$ & $\begin{array}{l}\text { Confirmed recurrent/metastatic ovarian, } \\
\text { vaginal, cervical, endometrial cancers }\end{array}$ & Median of 8 Gy $\times 5$ fractions & $\begin{array}{l}34 \% \text { stable disease, } 32 \% \\
\text { partial response and } 17 \% \\
\text { complete response at } 1 \text { year }\end{array}$ & $57 \%$ at 1 year \\
\hline
\end{tabular}


create the planning target volume, which is a margin on the clinical target volume to account for set-up uncertainties and organ motion. Treatments were prescribed to the $70 \%$ isodose line and delivered in three consecutive days. Target response rate (defined as complete or partial response) was $96 \%$ with duration of followup of 6 months. Median disease-free survival was 7.8 months and overall survival was 20.2 months with only 3 grade $\geq 3$ toxicities. These data are in line with results of salvage cytotoxic therapy in similar patients and the treatment is less intrusive for patients with limited survival.

Despite excellent local control, rates of progression outside of the targeted lesions remain high, ranging from 43 to $57 \%$ (65-67). These high rates of distant progression prompted a Phase I study with 12 women ( 7 with primary ovarian cancer) testing the safety of sequential carboplatin and gemcitabine followed by SBRT. This study showed that carboplatin AUC 4 and gemcitabine $600 \mathrm{mg} / \mathrm{m}^{2}$ can be given the day prior to SBRT using Cyberknife with the 8 Gy $\times 3$ fraction regimen with acceptable rates of toxicity. These reassuring results may pave the way for the addition of radiosensitizers, targeted agents, and immunotherapy in combination with SBRT (69-72).

\section{THE FUTURE OF RADIATION THERAPY IN OVARIAN CANCER}

Many of the toxicities of WAR in ovarian cancer are due to the large volume of tissue receiving a high dose of radiotherapy with little sparing of the organs at risk as well as minimal time for intrafraction repair of normal tissues. Over recent years, newer, more palatable fractionation schemes and advanced techniques, which allow sparing of at risk organs may allow for renewed interest in this treatment modality for this disease. Improved radiation techniques combined with an increasingly sophisticated understanding of molecular mechanisms leading to radiation and chemotherapy sensitivity are leading to innovative and novel therapies for patients with ovarian cancer.

\section{Intensity-Modulated Radiotherapy}

IMRT has replaced three dimensional conformal radiotherapy in the treatment of complex tumors, which are in close proximity to organs at risks such as in the treatment of prostate cancer, anal cancer, and head and neck malignancies. IMRT uses a computer algorithm to optimize dose to the target and minimize dose to organs at risk by modulating and shaping the beam either with static or dynamic beams. Rochet and colleagues examined the practicality of whole abdominal IMRT after surgical cytoreduction and chemotherapy in patients with advanced ovarian cancer. In the Phase I portion of the study (OVAR-IMRT-01), they treated 16 women (10 on study and 6 per protocol) with stage III disease ( $n=15$ had IIIC) (73). All women received optimal primary resection with $<1 \mathrm{~cm}$ residual disease followed by six cycles of carboplatin and docetaxel. The radiotherapy was delivered with either static beams or helical tomotherapy and was delivered to a dose of $30 \mathrm{~Gy}$ in 20 fractions (74). In order to accurately deliver conformal treatment, women were immobilized with vacuum bags and masks. The clinical target volume included the entire peritoneal cavity from the diaphragm to the Douglas cavity as well as the pelvic and para-aortic lymph nodes. The planning target volume was a $1.5 \mathrm{~cm}$ axial expansion and $2.5 \mathrm{~cm}$ superior-inferior expansion with $1 \mathrm{~cm}$ expansion into the liver, but no additional margin on the kidneys. In their study, all patients completed planned treatments with no interruptions and no acute grade 4 toxicities. Results are promising-with 4 years of follow-up, there have been relatively low rates of early severe toxicity although late toxicities include six small bowel obstructions, three due to adhesions and three from tumor recurrence. The recurrence-free survival was 27.6 months and median overall survival 42.1 months (75).

These results prompted the OVAR-IMRT-02 study-an ongoing single-center one arm phase-II trial. Thirty seven patients with optimally cytoreduced stage III ovarian cancer with a clinical complete remission after chemotherapy will be treated with intensity-modulated WAR as consolidation therapy (76). The primary endpoint is tolerability and the secondary objectives are toxicity, quality of life, progression free, and overall survival.

Figure 3 shows a comparison of an open-field three dimensional conformal radiotherapy plan with an intensity-modulated dynamic arc plan. The open-field plan is an AP-PA technique with a posterior kidney block to keep the mean dose to the kidneys $<18 \mathrm{~Gy}$. In order to encompass the large treatment volume, the open-field is treated at extended source to skin distance of $125 \mathrm{~cm}$ and the arc plan uses two isocenters with four arcs calculated on each. Arc techniques with helical tomotherapy, as used by Rochet et al. (74) are ideal as tomotherapy has a field width of $40 \mathrm{~cm}$ and length of $160 \mathrm{~cm}$ and the advantage of daily mega voltage CT setup.

On review of the dose volume histogram, the major differences between the two techniques is that, with the kidney blocks, there is a large dose gradient, which leads to dose heterogeneity with the three dimensional technique compared to superior coverage of the target volume with IMRT. With IMRT, the bone marrow and liver are able to be kept to lower doses, as shown in the sagittal and coronal images. The entire lung volume was not captured on this scan and, therefore, the volume receiving 20 Gy cannot be accurately calculated. However, IMRT does not significantly change the dose to the basal portions of the lungs and, therefore, would not be likely to reduce the risk of radiation pneumonitis. As one would expect with IMRT, a slightly higher volume of lung tissue receives a low dose and slightly lower volume receives a high dose or radiation, but the mean dose is similar. Increased conformality of IMRT comes at a cost, as it is much more labor intensive for the physician, dosimetrist, and physicist with many more contours, longer computer calculations, and more quality analysis. However, when planned, setup and treated carefully, the treatment is tolerable and potentially beneficial for the intermediate and high-risk groups of patients identified above.

\section{Low-Dose Fractionated Whole Abdominal Radiation As a Chemotherapy Sensitizer}

In the modern era, low-dose fractionated radiotherapy to the upper abdomen has been demonstrated to be well tolerated 


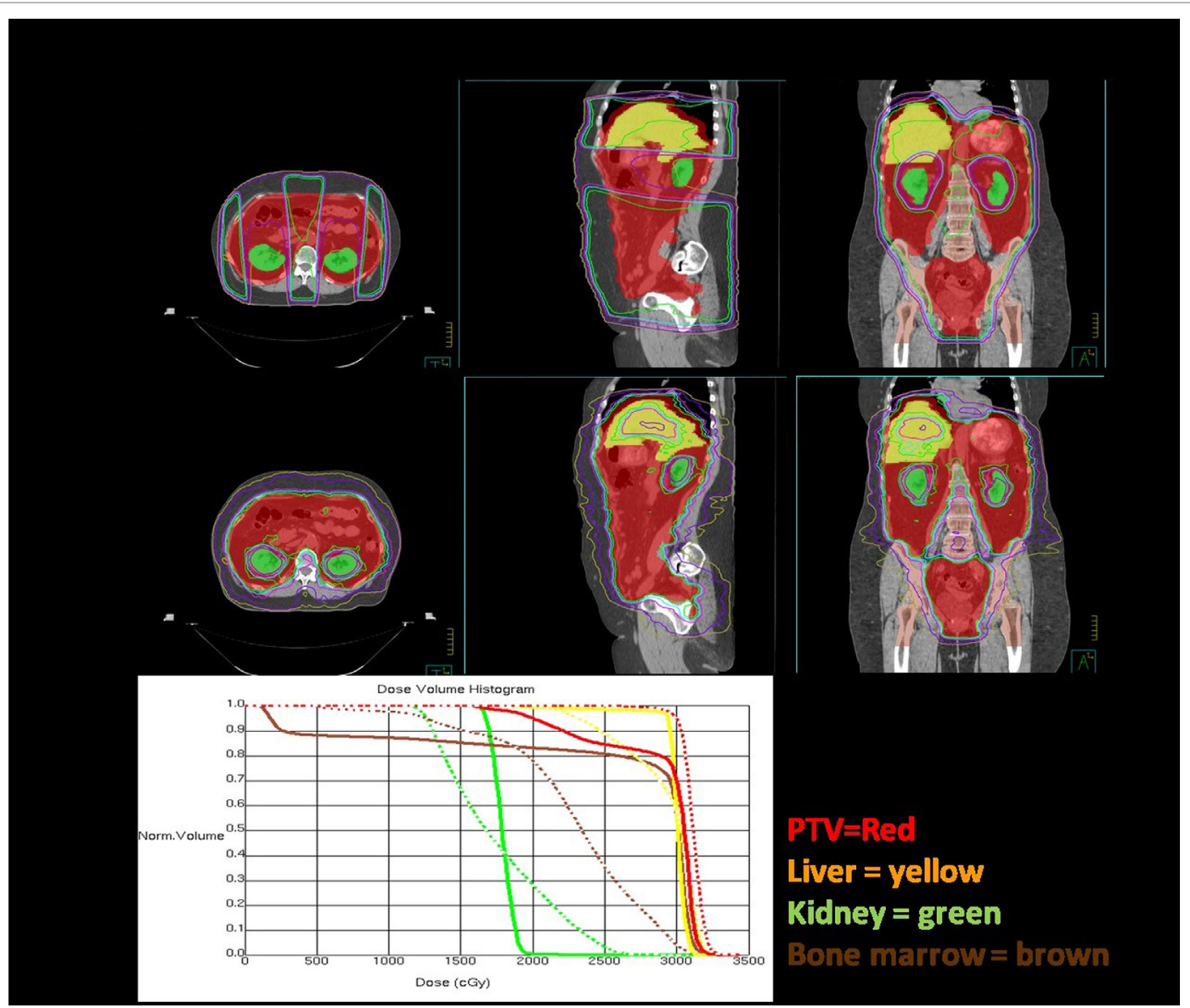

FIGURE 3 | Dosimetric comparisons of three dimensional conformal and intensity modulation radiation therapy (IMRT) plans for whole abdominal radiotherapy. The plans are each shown in axial, sagittal, and coronal orientations and the dose volume histogram comparison is below. The planning target volume (whole abdominal cavity) is red, liver is yellow, kidneys are green, and bone marrow is brown. The IMRT plan is the dashed lines and the 3DCRT plan DVH's are solid.

in combination with chemotherapy in several disease sites. Radiation-induced DNA damage may potentiate the effects of drugs such as gemcitabine and other antimetabolites that inhibit DNA synthesis by incorporating into new DNA strands as they are synthesized. Other potential mechanisms by which radiation and chemotherapy may act synergistically include changes in the microenvironment such as decreased hypoxia, stabilized vasculature, and enhanced immune activation $(77,78)$.

Low-dose fractionated WAR was combined with gemcitabine in patients with pancreatic cancer with acceptable toxicity in a small, single institutional trial (79). This led to a multi-institutional phase I study combining low-dose WAR with gemcitabine and erlotanib in patients with pancreatic cancer in which treatment was well tolerated with encouraging efficacy (80). The GOG administered WAR $(60 \mathrm{cGy} \times 2$ fractions daily, days 1 and 4 of each week for 6 weeks) as a chemosensitizer for dose-escalated weekly paclitaxel in women with recurrent ovarian, fallopian tube, or peritoneal cancers (9). Three (30\%) of 10 patients had stable disease for at least 6 months. Dose-limiting toxicities were primarily hematologic but also included one Grade 3 diarrhea.

Poly(ADP-ribose) polymerase (PARP) is an important family of enzymes activated in response to single-strand damage of DNA
$(81,82)$. Increased PARP activity is a well-described mechanism by which tumor cells avoid apoptosis caused by DNA damaging agents; it has been linked to drug resistance and the ability of tumor cells to withstand genotoxic stress (83-85). PARP inhibitors interrupt the catalytic effects of PARP and have demonstrated activity particularly in cancers with defects in homologous recombination such as ovarian cancers with BRCA mutations and other markers of homologous recombination repair (82). Although cancer cells with defective homologous recombination (e.g., BRCA mutated or platinum sensitive) are noted to have enhanced sensitivity to PARP inhibition, homologous recombination deficiency is not always an accurate predictive biomarker of PARP inhibitor activity $(86,87)$. The DNA damage induced by radiation may destabilize DNA repair systems within the cancer cell, allowing for enhanced activity of PARP inhibition (87-89).

In a preclinical model of the combination of PARP inhibition and radiation, significant cell death in vitro was demonstrated as well as inhibition of tumor growth in a pancreatic cancer mouse xenograft model (90). WAR (60 cGy $\times 2$ fractions daily, days 1 and 5 of each week for 3 weeks) was used as a chemosensitizer for dose-escalated twice-daily veliparib in patients with solid tumor 
malignancies associated with peritoneal carcinomatosis (91). Twelve (57\%) achieved stable disease, with seven (33\%) having stable disease for at least 6 months. Patients with gynecologic malignancy had the best responses and a platinum sensitive ovarian cancer patient with a germline BRCA mutation was an exceptional responder with a response of several years (91). A maximum tolerated dose of $250 \mathrm{mg}$ BID was identified in an expansion cohort of ovarian cancer patients with overall reasonable toxicity (92). Clinical trial of PARP inhibitors plus radiation therapy are ongoing in breast cancer, rectal, head and neck and non-small cell lung cancer (Table 3). A proposed randomized
Phase 2 trial of PARP inhibitor with or without radiation in ovarian cancer will provide additional insight into the role of the combination in this disease.

Radiation can induce multiple forms of DNA damage, which is repaired within the cell by various methods. Defective nonhomologous end joining (NHEJ) has been demonstrated in ovarian cancer cell lines (93). The inhibition of NHEJ leads to persistent DNA damage, which in turn leaves cells a more sensitive to radiation. Enhanced radiation response with inhibitors of NHEJ has been demonstrated in pancreatic cancer cell lines and may be rational in ovarian cancer as well (94).

TABLE 3 | Select ongoing clinical trials of radiation combinations.

\begin{tabular}{|c|c|c|c|c|c|}
\hline Description & Phase & Disease site & NCT number & Agent(s) & Sponsor \\
\hline $\begin{array}{l}\text { Olaparib and Radiotherapy in head and neck } \\
\text { cancer }\end{array}$ & I & $\begin{array}{l}\text { Squamous cell carcinoma of the } \\
\text { larynx stage II-III }\end{array}$ & NCT02229656 & Olaparib 25-300 mg BID & $\begin{array}{l}\text { The Netherlands } \\
\text { Cancer Institute }\end{array}$ \\
\hline $\begin{array}{l}\text { Phase I study of olaparib combined with } \\
\text { cisplatin-based chemoradiotherapy to treat locally }\end{array}$ & I & $\begin{array}{l}\text { High-risk locally advanced } \\
\text { HNSCC }\end{array}$ & NCT02308072 & $\begin{array}{l}\text { Olaparib } 50-200 \mathrm{mg} \text { BID } \\
\text { Cisplatin } 35 \mathrm{mg} / \mathrm{m}^{2} \mathrm{Q} \text { week }\end{array}$ & $\begin{array}{l}\text { Cancer Research } \\
\text { UK }\end{array}$ \\
\hline
\end{tabular}

advanced head and neck cancer (ORCA-2)

\begin{tabular}{|c|c|c|c|c|c|}
\hline $\begin{array}{l}\text { Olaparib and radiotherapy in inoperable breast } \\
\text { cancer }\end{array}$ & 1 & $\begin{array}{l}\text { Breast cancer or local recurrence of } \\
\text { breast cancer, which is inoperable } \\
\text { or/and metastatic, including } \\
\text { inflammatory breast cancer }\end{array}$ & NCT02227082 & Olaparib 25-400 mg BID & $\begin{array}{l}\text { The Netherlands } \\
\text { Cancer Institute }\end{array}$ \\
\hline $\begin{array}{l}\text { Veliparib with or without radiation therapy, } \\
\text { carboplatin, and paclitaxel in patients with stage III } \\
\text { non-small cell lung cancer that cannot be removed }\end{array}$ & $|/| \mid$ & $\begin{array}{l}\text { Unresectable stage IIIA/IIB, } \\
\text { non-small cell lung cancer }\end{array}$ & NCT01386385 & $\begin{array}{l}\text { Arm I Carboplatin, Paclitaxel } \\
\text { Arm II Carboplatin, Paclitaxel, } \\
\text { Velaparib }\end{array}$ & $\begin{array}{l}\text { NCl; Southwest } \\
\text { Oncology Group }\end{array}$ \\
\hline
\end{tabular}
by surgery

Veliparib and combination chemotherapy in treating patient with locally advanced rectal cancer
I Locally advanced adenocarcinoma of the rectum, Stage II/II
NCT02921256 Arm I (mFOLFOX6,

capecitabine)

Arm II (mFOLFOX6,

capecitabine, veliparib)

\section{Immunotherapy + radiation}

FLT3 ligand immunotherapy and stereotactic radiotherapy for advanced non-small cell lung cancer

Checkpoint blockade immunotherapy combined with stereotactic body radiotherapy in advanced metastatic disease

ProstAtak
Immunotherapy with standard radiation therapy for
localized prostate cancer

localized prostate cancer

ilimumab and stereotactic body radiotherapy (SBRT) in advanced solid tumors
II Stage III/IV non-small cell lung cancer not amenable to curative therapy Metastatic cancer with at least one lesion amenable to SBRT

NCT02839265

CTLA-4 and anti-PD-1 antibodies) with SBRT

III Localized prostate cancer meeting the NCCN criteria of intermediate risk or patients having only one NCCN high-risk feature
Arm I

ProstAtak ${ }^{\circledast}(\mathrm{AdV}$ -

tk) + valacyclovir

Arm II

Placebo + valacyclovir

NCT01436968

$\mathrm{NCl}$; NRG

Oncology

I/II Metastatic cancer with at least one NCT02239900 Ipilumumab with SBRT metastatic or primary lesion in the liver, lung, or adrenal gland

Pembrolizumab and chemoradiation treatment for advanced cervical cancer

I Locally advanced cervical cancer stage IB1 with lymph nodes or IB2-IVA

\section{NCT02635360 Arm I}

Cisplatin-based

chemoradiation

with consolidative

pembrolizumab $\times 3$ cycles

Arm II

Chemoradiation

with concurrent

Pembrolizumab $\times 3$ cycles
M.D. Anderson

Cancer Center; Bristol-Myers Squibb University of Virginia; Merck Sharp \& Dohme Corp
Albert Einstein

College of

University of California, San Diego Advantagene, Inc. 


\section{Abscopal Effect and Immunotherapy}

Immunotherapy has revolutionized cancer care over the last few years. The immune environment is crucial to prognosis in ovarian cancer and efforts are underway to translate this to novel therapeutic applications (95). The potential contribution of the immune system in response to radiation therapy has been demonstrated-induction of tumor associated antigens have been shown to develop after radiation in colorectal and prostate cancers (96-98).

The term "abscopal" was originally used in 1953 to describe the systemic effects of radiation on "out-of-field" tumor deposits (99). An abscopal effect of radiation presumably works through the release of tumor antigens occurring when radiation exerts DNA damage to a tumor site and likely related to systemic secretion of specific cytokines and chemokines triggering a systemic immune response against local tumor antigens (100-102). This effect has been demonstrated in preclinical and animal models as well as reported in several case series $(69,103-105)$. Several proof of principal trials are ongoing to determine whether the abscopal effect can be augmented by administering radiation therapy in conjunction with immune activating agents (Table 3 ).

Preclinical evidence suggest that cell kill by radiation therapy activates immune responses of dendritic cells, CD4+ T lymphocytes, and CD8+ T lymphocytes $(104,106)$. Two mechanisms

\section{REFERENCES}

1. Siegel RL, Miller KD, Jemal A. Cancer statistics, 2017. CA Cancer J Clin (2017) 67(1):7-30. doi:10.3322/caac.21387

2. Kurman RJ, Shih Ie M. Molecular pathogenesis and extraovarian origin of epithelial ovarian cancer - shifting the paradigm. Hum Pathol (2011) 42(7):918-31. doi:10.1016/j.humpath.2011.03.003

3. Jarboe EA, Folkins AK, Drapkin R, Ince TA, Agoston ES, Crum CP. Tubal and ovarian pathways to pelvic epithelial cancer: a pathological perspective. Histopathology (2009) 55(5):619. doi:10.1111/j.1365-2559.2009.03408.x

4. Steffensen KD, Waldstrom M, Grove A, Lund B, Pallisgard N, Jakobsen A. Improved classification of epithelial ovarian cancer: results of 3 Danish cohorts. Int J Gynecol Cancer (2011) 21(9):1592-600. doi:10.1097/ IGC.0b013e31822a0f6b

5. Kurman RJ, Shih Ie M. The dualistic model of ovarian carcinogenesis: revisited, revised, and expanded. Am J Pathol (2016) 186(4):733-47. doi:10.1016/j. ajpath.2015.11.011

6. Dembo AJ. Epithelial ovarian cancer: the role of radiotherapy. Int J Radiat Oncol Biol Phys (1992) 22(5):835-45. doi:10.1016/0360-3016(92)90777-F

7. May LF, Belinson JL, Roland TA. Palliative benefit of radiation therapy in advanced ovarian cancer. Gynecol Oncol (1990) 37(3):408-11. doi:10.1016/0090-8258(90)90377-W

8. Faul C, Gerszten K, Edwards R, Land S, D’Angelo G, Kelley J III, et al. A phase I/II study of hypofractionated whole abdominal radiation therapy in patients with chemoresistant ovarian carcinoma: Karnofsky score determines treatment outcome. Int J Radiat Oncol Biol Phys (2000) 47(3):749-54. doi:10.1016/S0360-3016(00)00446-6

9. Kunos C, Sill M, Buekers T, Walker J, Schilder J, Yamada S, et al. Low-dose abdominal radiation as a docetaxel chemosensitizer for recurrent epithelial ovarian cancer: a phase 1 study of the Gynecologic Oncology Group. Gynecol Oncol (2011) 120(2):224-8. doi:10.1016/j.ygyno.2010.10.018

10. Carey MS, Dembo AJ, Simm JE, Fyles AW, Treger T, Bush RS. Testing the validity of a prognostic classification in patients with surgically optimal ovarian carcinoma: a 15-year review. Int J Gynecol Cancer (1993) 3(1):24-35. doi:10.1046/j.1525-1438.1993.03010024.x

11. Cheng Y, Kiess AP, Herman JM, Pomper MG, Meltzer SJ, Abraham JM. Phosphorus-32, a clinically available drug, inhibits cancer growth by by which radiation has the potential to synergize with immunotherapy include (1) the generation of antigen-specific, adaptive immunity-act as sensitizer for anticancer agents-a phenomenon referred to as "in situ" vaccination, and (2) the induction of chemokine production to facilitate recruitment of effector T cells and reprogram the tumor microenvironment (103).

\section{CONCLUSION}

Ovarian cancer has demonstrated sensitivity to radiation therapy. Toxicity in the historical setting has limited present day use of this treatment modality. However, an updated understanding of the molecular differences of distinct histologic subtypes of ovarian cancer with differential response to both chemotherapy and radiation therapy has generated renewed interest in the potential application of radiation therapy in ovarian cancer.

\section{AUTHOR CONTRIBUTIONS}

EF and ST participated in developing the concept of this manuscript, researching and writing, manuscript preparation, and approval of the final manuscript draft. WM and LL participated in researching and writing this manuscript, manuscript preparation, and approval of the final manuscript draft. inducing DNA double-strand breakage. PLoS One (2015) 10(6):e0128152. doi:10.1371/journal.pone.0128152

12. Rosenshein NB, Leichner PK, Vogelsang G. Radiocolloids in the treatment of ovarian cancer. Obstet Gynecol Surv (1979) 34(9):708-20. doi:10.1097/00006254-197909000-00028

13. Potter ME, Partridge EE, Shingleton HM, Soong S-J, Kim RY, Hatch KD, et al. Intraperitoneal chromic phosphate in ovarian cancer: risks and benefits. Gynecol Oncol (1989) 32(3):314-8. doi:10.1016/0090-8258(89) 90631-8

14. Buchsbaum H, Keettel W. Radioisotopes in treatment of stage Ia ovarian cancer. Natl Cancer Inst Monogr (1975) 42:127.

15. Reddy S, Sutton G, Stehman FB, Hornback N, Ehrlich C. Ovarian carcinoma: adjuvant treatment with P-32. Radiology (1987) 165(1):275-8. doi:10.1148/ radiology.165.1.3628782

16. Soper JT, Wilkinson RH Jr, Bandy LC, Clarke-Pearson DL, Creasman WT. Intraperitoneal chromic phosphate P 32 as salvage therapy for persistent carcinoma of the ovary after surgical restaging. Am J Obstet Gynecol (1987) 156(5):1153-8. doi:10.1016/0002-9378(87)90131-1

17. Tharp M, Hornback NB. Complications associated with intraperitoneal 32P. Gynecol Oncol (1994) 53(2):170-5. doi:10.1006/gyno.1994.1111

18. Klaassen D, Starreveld A, Shelly W, Miller A, Boyes D, Gerulath A, et al. External beam pelvic radiotherapy plus intraperitoneal radioactive chronic phosphate in early stage ovarian cancer: a toxic combination. Int J Radiat Oncol Biol Phys (1985) 11(10):1801-4. doi:10.1016/0360-3016(85) 90035-5

19. Varia MA, Stehman FB, Bundy BN, Benda JA, Clarke-Pearson DL, Alvarez $\mathrm{RD}$, et al. Intraperitoneal radioactive phosphorus (32P) versus observation after negative second-look laparotomy for stage III ovarian carcinoma: a randomized trial of the gynecologic oncology group. J Clin Oncol (2003) 21(15):2849-55. doi:10.1200/JCO.2003.11.018

20. Young RC, Walton LA, Ellenberg SS, Homesley HD, Wilbanks GD, Decker DG, et al. Adjuvant therapy in stage I and stage II epithelial ovarian cancer. $N$ Engl J Med (1990) 322(15):1021-7. doi:10.1056/ NEJM199004123221501

21. Vergote IB, Vergote-De Vos LN, Abeler VM, Aas M, Lindegaard MW, Kjørstad KE, et al. Randomized trial comparing cisplatin with radioactive phosphorus or whole-abdomen irradiation as adjuvant treatment of 
ovariancancer.Cancer(1992)69(3):741-9.doi:10.1002/1097-0142(19920201) 69:3<741::AID-CNCR2820690322>3.0.CO;2-G

22. Bolis G, Colombo N, Pecorelli S, Torri V, Marsoni S, Bonazzi C, et al. Adjuvant treatment for early epithelial ovarian cancer: results of two randomised clinical trials comparing cisplatin to no further treatment or chromic phosphate (32P). Ann Oncol (1995) 6(9):887-93. doi:10.1093/oxfordjournals.annonc. a059355

23. Young RC, Brady MF, Nieberg RK, Long HJ, Mayer AR, Lentz SS, et al. Adjuvant treatment for early ovarian cancer: a randomized phase III trial of intraperitoneal 32P or intravenous cyclophosphamide and cisplatin-a gynecologic oncology group study. JClin Oncol (2003) 21(23):4350-5. doi:10.1200/JCO.2003.02.154

24. McGuire WP. Early ovarian cancer: treat now, later or never? Ann Oncol (1995) 6(9):865-6. doi:10.1093/oxfordjournals.annonc.a059351

25. Coleman R, Coleman F. Radiation therapy in the management of epithelial ovarian cancer. Glob Libr Womens Med (2008). doi:10.3843/GLOWM.10254

26. Thomas GM, Dembo AJ. Integrating radiation therapy into the management of ovarian cancer. Cancer (1993) 71(S4):1710-8. doi:10.1002/ cncr.2820710441

27. Fazekas J, Maier J. Irradiation of ovarian carcinomas: a prospective comparison of the open-field and moving-strip techniques. Am J Roentgenol Radium Ther Nucl Med (1974) 120(1):118-23. doi:10.2214/ajr.120.1.118

28. Dembo A, Bush R, Beale F, Bean H, Brown T, Fine S, et al. A randomized clinical trial of moving strip versus open field whole abdominal irradiation in patients with invasive epithelial cancer of ovary. Int Radiat Oncol Biol Phys (1983) 9:97.

29. Smith JP, Rutledge FN, Delclos L. Postoperative treatment of early cancer of the ovary: a random trial between postoperative irradiation and chemotherapy. Natl Cancer Inst Monogr (1975) 42:149-53.

30. Dembo AJ. The role of radiotherapy in ovarian cancer. Bull Cancer (1982) 69(3):275-83.

31. Klaassen D, Shelley W, Starreveld A, Kirk M, Boyes D, Gerulath A, et al. Early stage ovarian cancer: a randomized clinical trial comparing whole abdominal radiotherapy, melphalan, and intraperitoneal chromic phosphate: a National Cancer Institute of Canada Clinical Trials Group report. J Clin Oncol (1988) 6(8):1254-63. doi:10.1200/JCO.1988.6.8.1254

32. Redman CWE, Mould J, Warwick J, Rollason T, Luesley DM, Budden J, et al. The west Midlands epithelial ovarian cancer adjuvant therapy trial. Clin Oncol (1993) 5(1):1-5. doi:10.1016/S0936-6555(05)80682-X

33. Sell A, Bertelsen K, Andersen J, Strøyer I, Panduro J. Randomized study of whole-abdomen irradiation versus pelvic irradiation plus cyclophosphamide in treatment of early ovarian cancer. Gynecol Oncol (1990) 37(3):367-73. doi:10.1016/0090-8258(90)90369-V

34. Chiara S, Conte PF, Franzone P, Orsatti M, Bruzzone M, Rubagotti A, et al. High-risk early-stage ovarian cancer: randomized clinical trial comparing cisplatin plus cyclophosphamide versus whole abdominal radiotherapy. Am J Clin Oncol (1994) 17(1):72-6. doi:10.1097/00000421-199402000-00016

35. Kojs Z, Glinski B, Reinfuss M, Pudelek J, Urbanski K, Kowalska T, et al. Résultats d'un essai prospectif randomisé comparant une radiothérapie abdominopelvienne postopératoire et une chimiothérapie postopératoire dans les cancers de lovaire précoces. Cancer Radiothér (2001) 5(1):5-11. doi:10.1016/S1278-3218(00)00022-6

36. Hreshchyshyn MM, Park RC, Blessing JA, Norris HJ, Levy D, Lagasse LD, et al. The role of adjuvant therapy in stage I ovarian cancer. Am J Obstet Gynecol (1980) 138(2):139-45. doi:10.1016/0002-9378(80)90024-1

37. Lawton F, Luesley D, Blackledge G, Hilton C, Kelly K, Latief T, et al. A randomized trial comparing whole abdominal radiotherapy with chemotherapy following cisplatinum cytoreduction in epithelial ovarian cancer. West Midlands Ovarian Cancer Group Trial II. Clin Oncol (1990) 2(1):4-9. doi:10.1016/S0936-6555(05)80210-9

38. Hoskins P, Swenerton K, Wong F, Manji M, McMurtrie E, Le N, et al. Platinum plus cyclophosphamide plus radiotherapy is superior to platinum alone in 'high-risk' epithelial ovarian cancer (residual negative and either stage I or II, grade 3, or stage III, any grade). Int J Gynecol Cancer (1995) 5(2):134-42. doi:10.1046/j.1525-1438.1995.05020134.x

39. Lambert HE, Rustin GJS, Gregory WM, Nelstrop AE. A randomized trial comparing single-agent carboplatin with carboplatin followed by radiotherapy for advanced ovarian cancer: a North Thames Ovary Group Study. J Clin Oncol (1993) 11(3):440-8. doi:10.1200/JCO.1993.11.3.440
40. Pickel H, Lahousen M, Petru E, Stettner H, Hackl A, Kapp K, et al. Consolidation radiotherapy after carboplatin-based chemotherapy in radically operated advanced ovarian cancer. Gynecol Oncol (1999) 72(2):215-9. doi:10.1006/gyno.1998.5184

41. Sorbe B; Swedish-Norgewian Ovarian Cancer Study Group. Consolidation treatment of advanced (FIGO stage III) ovarian carcinoma in complete surgical remission after induction chemotherapy: a randomized, controlled, clinical trial comparing whole abdominal radiotherapy, chemotherapy, and no further treatment. Int J Gynecol Cancer (2003) 13(3):278-86. doi:10.1046/j.1525-1438.2003.13193.x

42. Peters WA, Blasko JC, Bagley CM, Rudolph RH, Smith MR, Rivkin SE. Salvage therapy with whole-abdominal irradiation in patients with advanced carcinoma of the ovary previously treated by combination chemotherapy. Cancer (1986) 58(4):880-2. doi:10.1002/1097-0142(19860815)58:4<880::AID-CNCR2820580413>3.0.CO;2-Z

43. Haie C, Pejovic-Lenfant MH, George M, Michel G, Gerbaulet A, Prade $\mathrm{M}$, et al. Whole abdominal irradiation following chemotherapy in patients with minimal residual disease after second look surgery in ovarian carcinoma. Int J Radiat Oncol Biol Phys (1989) 17(1):15-9. doi:10.1016/ 0360-3016(89)90364-7

44. Bolis G, Zanaboni F, Vanoli P, Russo A, Franchi M, Scarfone G, et al. The impact of whole-abdomen radiotherapy on survival in advanced ovarian cancer patients with minimal residual disease after chemotherapy. Gynecol Oncol (1990) 39(2):150-4. doi:10.1016/0090-8258(90)90423-I

45. Thomas L, Pigneux J, Chauvergne J, Stöckle E, Bussiéres E, Chemin A, et al. Evaluation of whole abdominal irradiation in ovarian carcinoma with a four orthogonal fields technique. Int J Radiat Oncol Biol Phys (1994) 30(5):1083-90. doi:10.1016/0360-3016(94)90313-1

46. Kuten A, Stein M, Steiner M, Rubinov R, Epelbaum R, Cohen $Y$. Whole abdominal irradiation following chemotherapy in advanced ovarian carcinoma. Int J Radiat Oncol Biol Phys (1988) 14(2):273-9. doi:10.1016/0360-3016(88)90432-4

47. Patel SC, Frandsen J, Bhatia S, Gaffney D. Impact on survival with adjuvant radiotherapy for clear cell, mucinous, and endometriod ovarian cancer: the SEER experience from 2004 to 2011. J Gynecol Oncol (2016) 27(5):e45. doi:10.3802/jgo.2016.27.e45

48. Del Carmen MG, Birrer M, Schorge JO. Clear cell carcinoma of the ovary: a review of the literature. Gynecol Oncol (2012) 126(3):481-90. doi:10.1016/j. ygyno.2012.04.021

49. Hoskins PJ, Le N, Gilks B, Tinker A, Santos J, Wong F, et al. Low-stage ovarian clear cell carcinoma: population-based outcomes in British Columbia, Canada, with evidence for a survival benefit as a result of irradiation. J Clin Oncol (2012) 30(14):1656-62. doi:10.1200/JCO.2011.40.1646

50. Nagai $Y$, Inamine M, Hirakawa M, Kamiyama K, Ogawa K, Toita T, et al. Postoperative whole abdominal radiotherapy in clear cell adenocarcinoma of the ovary. Gynecol Oncol (2007) 107(3):469-73. doi:10.1016/j. ygyno.2007.07.079

51. Swenerton KD, Santos JL, Gilks CB, Köbel M, Hoskins PJ, Wong F, et al. Histotype predicts the curative potential of radiotherapy: the example of ovarian cancers. Ann Oncol (2011) 22(2):341-7. doi:10.1093/annonc/ mdq383

52. Hogen L, Thomas G, Bernardini M, Bassiouny D, Brar H, Gien LT, et al. The effect of adjuvant radiation on survival in early stage clear cell ovarian carcinoma. Gynecol Oncol (2016) 143(2):258-63. doi:10.1016/j.ygyno.2016.09.006

53. Macrie BD, Strauss JB, Helenowski IB, Rademaker A, Schink JC, Lurain JR, et al. Patterns of recurrence and role of pelvic radiotherapy in ovarian clear cell adenocarcinoma. Int J Gynecol Cancer (2014) 24(9):1597-602. doi:10.1097/IGC.0000000000000270

54. Brown AP, Jhingran A, Klopp AH, Schmeler KM, Ramirez PT, Eifel PJ. Involved-field radiation therapy for locoregionally recurrent ovarian cancer. Gynecol Oncol (2013) 130(2):300-5. doi:10.1016/j.ygyno.2013.04.469

55. Albuquerque KV, Singla R, Potkul RK, Smith DM, Creech S, Lo S, et al. Impact of tumor volume-directed involved field radiation therapy integrated in the management of recurrent ovarian cancer. Gynecol Oncol (2005) 96(3):701-4. doi:10.1016/j.ygyno.2004.11.008

56. Albuquerque K, Patel M, Liotta M, Harkenrider M, Guo R, Small W Jr, et al. Long-term benefit of tumor volume-directed involved field radiation therapy in the management of recurrent ovarian cancer. Int J Gynecol Cancer (2016) 26(4):655-60. doi:10.1097/IGC.0000000000000653 
57. Machida S, Takei Y, Yoshida C, Takahashi Y, Koyanagi T, Sato N, et al. Radiation therapy for chemotherapy-resistant recurrent epithelial ovarian cancer. Oncology (2014) 86(4):232-8. doi:10.1159/000357269

58. Fong Y, Fortner J, Sun RL, Brennan MF, Blumgart LH. Clinical score for predicting recurrence after hepatic resection for metastatic colorectal cancer: analysis of 1001 consecutive cases. Ann Surg (1999) 230(3):309-18; discussion 18-21. doi:10.1097/00000658-199909000-00004

59. Rusthoven KE, Kavanagh BD, Burri SH, Chen C, Cardenes H, Chidel MA, et al. Multi-institutional phase I/II trial of stereotactic body radiation therapy for lung metastases. J Clin Oncol (2009) 27(10):1579-84. doi:10.1200/ JCO.2008.19.6386

60. Rusthoven KE, Kavanagh BD, Cardenes H, Stieber VW, Burri SH, Feigenberg SJ, et al. Multi-institutional phase I/II trial of stereotactic body radiation therapy for liver metastases. J Clin Oncol (2009) 27(10):1572-8. doi:10.1200/JCO.2008.19.6386

61. Kunos C, Brindle JM, Debernardo R. Stereotactic radiosurgery for gynecologic cancer. J Vis Exp (2012) (62):3793. doi:10.3791/3793

62. Kunos C, Chen W, DeBernardo R, Waggoner S, Brindle J, Zhang Y, et al. Stereotactic body radiosurgery for pelvic relapse of gynecologic malignancies. Technol Cancer Res Treat (2009) 8(5):393-400. doi:10.1177/153303460900800510

63. Kunos CA, Spelic M. Role of stereotactic radiosurgery in gynecologic cancer. Curr Opin Oncol (2013) 25(5):532-8. doi:10.1097/CCO.0b013e328363e0ad

64. Mayr NA, Huang Z, Sohn JW, Lo SS, Teh BS, Lu JJ, et al. Emerging application of stereotactic body radiation therapy for gynecologic malignancies. Expert Rev Anticancer Ther (2011) 11(7):1069-75. doi:10.1586/era.11.81

65. Deodato F, Macchia G, Grimaldi L, Ferrandina G, Lorusso D, Salutari V, et al. Stereotactic radiotherapy in recurrent gynecological cancer: a case series. Oncol Rep (2009) 22(2):415-9. doi:10.3892/or_00000453

66. Higginson DS, Morris DE, Jones EL, Clarke-Pearson D, Varia MA. Stereotactic body radiotherapy (SBRT): technological innovation and application in gynecologic oncology. Gynecol Oncol (2011) 120(3):404-12. doi:10.1016/j. ygyno.2010.11.042

67. Mesko S, Sandler K, Cohen J, Konecny G, Steinberg M, Kamrava M. Clinical outcomes for stereotactic ablative radiotherapy in oligometastatic and oligoprogressive gynecological malignancies. Int J Gynecol Cancer (2017) 27(2):403-8. doi:10.1097/IGC.0000000000000869

68. Kunos CA, Sherertz TM, Mislmani M, Ellis RJ, Lo SS, Waggoner SE, et al. Phase I trial of carboplatin and gemcitabine chemotherapy and stereotactic ablative radiosurgery for the palliative treatment of persistent or recurrent gynecologic cancer. Front Oncol (2015) 5:126. doi:10.3389/fonc.2015.00126

69. Crittenden M, KohrtH, Levy R, Jones J, Camphausen K, Dicker A, et al. Current clinical trials testing combinations of immunotherapy and radiation. Semin Radiat Oncol (2015) 25(1):54-64. doi:10.1016/j.semradonc.2014.07.003

70. Demaria S, Coleman CN, Formenti SC. Radiotherapy: changing the game in immunotherapy. Trends Cancer (2016) 2(6):286-94. doi:10.1016/j. trecan.2016.05.002

71. Formenti SC. Is classical stereotactic radiotherapy the optimal partner for immunotherapy? Oncology (2015) 29(5):340, 347, 387.

72. Formenti SC, Demaria S. Combining radiotherapy and cancer immunotherapy: a paradigm shift. J Natl Cancer Inst (2013) 105(4):256-65. doi:10.1093/ jnci/djs629

73. Rochet N, Jensen AD, Sterzing F, Munter MW, Eichbaum MH, Schneeweiss A, et al. Adjuvant whole abdominal intensity modulated radiotherapy (IMRT) for high risk stage FIGO III patients with ovarian cancer (OVAR-IMRT-01) - pilot trial of a phase I/II study: study protocol. BMC Cancer (2007) 7:227. doi:10.1186/1471-2407-7-227

74. Rochet N, Sterzing F, Jensen A, Dinkel J, Herfarth K, Schubert K, et al. Helical tomotherapy as a new treatment technique for whole abdominal irradiation. Strahlenther Onkol (2008) 184(3):145-9. doi:10.1007/s00066-0081772-z

75. Rochet N, Lindel K, Katayama S, Schubert K, Herfarth K, Schneeweiss A, et al. Intensity-modulated whole abdomen irradiation following adjuvant carboplatin/taxane chemotherapy for FIGO stage III ovarian cancer: four-year outcomes. Strahlenther Onkol (2015) 191(7):582-9. doi:10.1007/ s00066-015-0830-6

76. Rochet N, Kieser M, Sterzing F, Krause S, Lindel K, Harms W, et al. Phase II study evaluating consolidation whole abdominal intensity-modulated radiotherapy (IMRT) in patients with advanced ovarian cancer stage FIGO
III - The OVAR-IMRT-02 Study. BMC Cancer (2011) 11:41. doi:10.1186/ 1471-2407-11-41

77. Shinohara ET, Maity A. Increasing sensitivity to radiotherapy and chemotherapy by using novel biological agents that alter the tumor microenvironment. Curr Mol Med (2009) 9(9):1034-45. doi:10.2174/156652409789839107

78. Reichert ZR, Wahl DR, Morgan MA. Translation of targeted radiation sensitizers into clinical trials. Semin Radiat Oncol (2016) 26(4):261-70. doi:10.1016/j.semradonc.2016.06.001

79. Regine WF, Hanna N, Garofalo MC, Doyle A, Arnold S, Kataria R, et al. Low-dose radiotherapy as a chemopotentiator of gemcitabine in tumors of the pancreas or small bowel: a phase I study exploring a new treatment paradigm. Int J Radiat Oncol Biol Phys (2007) 68(1):172-7. doi:10.1016/j. ijrobp.2006.11.045

80. Konski A, Meyer JE, Joiner M, Hall MJ, Philip P, Shields A, et al. Multiinstitutional phase I study of low-dose ultra-fractionated radiotherapy as a chemosensitizer for gemcitabine and erlotinib in patients with locally advanced or limited metastatic pancreatic cancer. Radiother Oncol (2014) 113(1):35-40. doi:10.1016/j.radonc.2014.08.014

81. Petermann E, Keil C, Oei SL. Poly-ADP-ribosylation in health and disease. Cell Mol Life Sci (2005) 62(7):731-8. doi:10.1007/s00018-004-4504-2

82. Ledermann JA. PARP inhibitors in ovarian cancer. Ann Oncol (2016) 27(Suppl_1):i40-4. doi:10.1093/annonc/mdw094

83. Gelmon KA, Tischkowitz M, Mackay H, Swenerton K, Robidoux A, Tonkin $\mathrm{K}$, et al. Olaparib in patients with recurrent high-grade serous or poorly differentiated ovarian carcinoma or triple-negative breast cancer: a phase 2, multicentre, open-label, non-randomised study. Lancet Oncol (2011) 12(9):852-61. doi:10.1016/S1470-2045(11)70214-5

84. Farmer H, McCabe N, Lord CJ, Tutt ANJ, Johnson DA, Richardson TB, et al. Targeting the DNA repair defect in BRCA mutant cells as a therapeutic strategy. Nature (2005) 434(7035):917-21. doi:10.1038/nature03445

85. Fong PC, Boss DS, Yap TA, Tutt A, Wu P, Mergui-Roelvink M, et al. Inhibition of poly(ADP-ribose) polymerase in tumors from BRCA mutation carriers. N Engl J Med (2009) 361(2):123-34. doi:10.1056/NEJMoa0900212

86. Mirza MR, Monk BJ, Herrstedt J, Oza AM, Mahner S, Redondo A, et al. Niraparib maintenance therapy in platinum-sensitive, recurrent ovarian cancer. N Engl J Med (2016) 375(22):2154-64. doi:10.1056/NEJMoa1611310

87. Stover EH, Konstantinopoulos PA, Matulonis UA, Swisher EM. Biomarkers of response and resistance to DNA repair targeted therapies. Clin Cancer Res (2016) 22(23):5651-60. doi:10.1158/1078-0432.CCR-16-0247

88. Yang S-H, Kuo T-C, Wu H, Guo J-C, Hsu C, Hsu C-H, et al. Perspectives on the combination of radiotherapy and targeted therapy with DNA repair inhibitors in the treatment of pancreatic cancer. World J Gastroenterol (2016) 22(32):7275-88. doi:10.3748/wjg.v22.i32.7275

89. Provencio M, Sánchez A. Therapeutic integration of new molecule-targeted therapies with radiotherapy in lung cancer. Transl Lung Cancer Res (2014) 3(2):89-94. doi:10.3978/j.issn.2218-6751.2014.03.06

90. Tuli R, Surmak AJ, Reyes J, Armour M, Hacker-Prietz A, Wong J, et al. Radiosensitization of pancreatic cancer cells in vitro and in vivo through poly (ADP-ribose) polymerase inhibition with ABT-888. Transl Oncol (2014) 7(3):439-45. doi:10.1016/j.tranon.2014.04.003

91. Reiss KA, Herman JM, Zahurak M, Brade A, Dawson LA, Scardina A, et al. A Phase I study of veliparib (ABT-888) in combination with low-dose fractionated whole abdominal radiation therapy in patients with advanced solid malignancies and peritoneal carcinomatosis. Clin Cancer Res (2015) 21(1):68-76. doi:10.1158/1078-0432.CCR-14-1552

92. Reiss KA, Herman JM, Armstrong D, Zahurak M, Fyles A, Brade A, et al. A final report of a phase I study of veliparib (ABT-888) in combination with low-dose fractionated whole abdominal radiation therapy (LDFWAR) in patients with advanced solid malignancies and peritoneal carcinomatosis with a dose escalation in ovarian and fallopian tube cancers. Gynecol Oncol (2017) 144(3):486-90. doi:10.1016/j.ygyno.2017.01.016

93. McCormick A, Donoghue P, Dixon M, O'Sullivan R, O'Donnell RL, Murray J, et al. Ovarian cancers harbor defects in nonhomologous end joining resulting in resistance to rucaparib. Clin Cancer Res (2017) 23(8):2050-60. doi:10.1158/1078-0432.CCR-16-0564

94. Li Y-H, Wang X, Pan Y, Lee D-H, Chowdhury D, Kimmelman AC. Inhibition of non-homologous end joining repair impairs pancreatic cancer growth and enhances radiation response. PLoS One (2012) 7(6):e39588. doi:10.1371/journal.pone.0039588 
95. Turner TB, Buchsbaum DJ, Straughn JM Jr, Randall TD, Arend RC. Ovarian cancer and the immune system-the role of targeted therapies. Gynecol Oncol (2016) 142(2):349-56. doi:10.1016/j.ygyno.2016.05.007

96. Nesslinger NJ, Sahota RA, Stone B, Johnson K, Chima N, King C, et al. Standard treatments induce antigen-specific immune responses in prostate cancer. Clin Cancer Res (2007) 13(5):1493-502. doi:10.1158/1078-0432. CCR-06-1772

97. Schaue D, Comin-Anduix B, Ribas A, Zhang L, Goodglick L, Sayre JW, et al. T-cell responses to survivin in cancer patients undergoing radiation therapy. Clin Cancer Res (2008) 14(15):4883-90. doi:10.1158/1078-0432. CCR-07-4462

98. Gulley JL, Arlen PM, Bastian A, Morin S, Marte J, Beetham P, et al. Combining a recombinant cancer vaccine with standard definitive radiotherapy in patients with localized prostate cancer. Clin Cancer Res (2005) 11(9):3353-62. doi:10.1158/1078-0432.CCR-04-2062

99. Mole RH. Whole body irradiation-radiobiology or medicine? Br J Radiol (1953) 26(305):234-41. doi:10.1259/0007-1285-26-305-234

100. Siva S, MacManus MP, Martin RF, Martin OA. Abscopal effects of radiation therapy: a clinical review for the radiobiologist. Cancer Lett (2015) 356(1):82-90. doi:10.1016/j.canlet.2013.09.018

101. Demaria S, Ng B, Devitt ML, Babb JS, Kawashima N, Liebes L, et al. Ionizing radiation inhibition of distant untreated tumors (abscopal effect) is immune mediated. Int J Radiat Oncol Biol Phys (2004) 58(3):862-70. doi:10.1016/j. ijrobp.2003.09.012

102. Kaur P, Asea A. Radiation-induced effects and the immune system in cancer. Front Oncol (2012) 2:191. doi:10.3389/fonc.2012.00191
103. Herrera FG, Bourhis J, Coukos G. Radiotherapy combination opportunities leveraging immunity for the next oncology practice. CA Cancer JClin (2017) 67(1):65-85. doi:10.3322/caac.21358

104. Dewan MZ, Galloway AE, Kawashima N, Dewyngaert JK, Babb JS, Formenti SC, et al. Fractionated but not single-dose radiotherapy induces an immune-mediated abscopal effect when combined with anti-CTLA-4 antibody. Clin Cancer Res (2009) 15(17):5379-88. doi:10.1158/1078-0432. CCR-09-0265

105. Formenti SC, Demaria S. Systemic effects of local radiotherapy. Lancet Oncol (2009) 10(7):718-26. doi:10.1016/S1470-2045(09)70082-8

106. Derer A, Deloch L, Rubner Y, Fietkau R, Frey B, Gaipl US. Radioimmunotherapy-induced immunogenic cancer cells as basis for induction of systemic anti-tumor immune responses - pre-clinical evidence and ongoing clinical applications. Front Immunol (2015) 6:505. doi:10.3389/ fimmu.2015.00505

Conflict of Interest Statement: The authors declare that the research was conducted in the absence of any commercial or financial relationships that could be construed as a potential conflict of interest.

Copyright (c) 2017 Fields, McGuire, Lin and Temkin. This is an open-access article distributed under the terms of the Creative Commons Attribution License (CC BY). The use, distribution or reproduction in other forums is permitted, provided the original author(s) or licensor are credited and that the original publication in this journal is cited, in accordance with accepted academic practice. No use, distribution or reproduction is permitted which does not comply with these terms. 